\title{
REFERENCIAIS TEÓRICOS-METODOLOGICOS: SEQUENCIAS DIDÁTICAS COM TECNOLOGIAS NO ENSINO DE MATEMÁTICA NA EDUCAÇÃO BÁSICA
}

\section{THEORETICAL-METHODOLOGICAL REFERENCES: DIDACTIC SEQUENCES WITH TECHNOLOGIES IN THE TEACHING OF MATHEMATICS IN BASIC EDUCATION}

\author{
Edvaldo Lopes do Nascimento \\ UNICSUL - Aluno do Programa de Pós-Graduação Mestrado no Ensino de Ciências e \\ Matemática, edvaldo_lopes@bol.com.br \\ Juliano Schmiguel \\ UNICSUL - Professor do Programa de Pós-Graduação Mestrado e Doutorado, \\ schimiguel@gmail.com
}

\section{Resumo}

Neste artigo apresentamos uma análise das pesquisas envolvendo as Tecnologias Digitais e seu uso na sala de aula. Nosso cenário de investigação foi constituido pelas publicações que abordam essa temática no site Banco de Teses e Dissertações da Capes. Como procedimento metodologico realizamos a análise dos textos encontrados onde se combinava elementos teóricos e metodologicos que pudessem ser reproduzidos em sala de aula no ensino de Matemática, assim, doze sequencias didáticas que traduziam bem o objetivo de fornecer ao professor arsenal prático e exemplos para que tenha otimização do seu tempo e capacitação em atender as necessidades da presente geração. Seus resultados foram apontados como favoráveis ao ensino aprendizagem e podem contribuir para que o professor tenha uma melhor qualidade no aproveitamento do seu contato com o aluno.

Palavras-chave: Teorias de Ensino Aprendizagem; TICs; Sequência Didática;

In this article we present an analysis of the researches involving the Digital Technologies and their use in the classroom. Our research scenario was constituted by the publications that approach this subject in the site Bank of Thesis and Dissertations of Capes. As a methodological procedure we performed the analysis of the texts found where theoretical and methodological elements that could be reproduced in the classroom in the teaching of Mathematics were combined, thus twelve didactic sequences that translated the objective of providing the teacher with practical arsenal and examples so that Optimization of their time and capacity to meet the needs of the present generation. Their results were pointed out as favorable to teaching learning and can contribute to the teacher having a better quality in the use of his contact with the student.

Keywords: Teaching Theories Learning; TICs; Following teaching; 


\section{Introdução}

Em todos os contextos e áreas em nossa sociedade vemos a tecnologia sendo utilizada, mas quando observamos a área educacional mais precisamente no ensinoaprendizagem a tecnologia tem sido subutilizada. As transformações tecnológicas impõe novos ritmos, novas percepções, surgindo assim mudança no comportamento e no ensinoaprendizagem. Com essas mudanças percebemos um descompasso entre a geração que ensina e a de quem aprende. Seria talvez o receio do professor ser substituído pela tecnologia? Os profissionais da educação por não compreenderem o lugar da tecnologia acabam tendo receio que o uso da tecnologia traria desemprego, mas temos pesquisadores e pesquisas que mostram que a tecnologia na área educacional poderia ser uma aliada do professor, pois o que elas fazem justamente é ampliar e intensificar as possibilidades cognitivas e interativas no processo de construção de conhecimentos (ASSMANN,2000,p.8).

Não encontraríamos no contexto das tecnologias um aliado para atender uma geração mais do que acostumada a tecnologia? Alunos conectados o tempo inteiro é a nova realidade., eles lidam com celulares, Ipod, tablets, videogames, smartphones etc.Conforme declara o lbid(2005):

O Homem é um ser destinado a viver necessariamente na natureza. Apenas, o que se entende por "natureza" em cada fase histórica corresponde a uma realidade diferente. Se no inicio era o mundo espontaneamente constituído, agora que o civilizado consegue cercar-se de produtos fabricados pela arte e pela ciência, serão estes que formarão para ele a nova "natureza". (IBID,2005, v.1,p.37)

Essa nova "natureza" descrita acima precisa ser melhor compreendida pelos Professores, quando enfatizam com frequência da falta de interesse do aluno pelos estudos,o aproveitamento em provas e testes diversos sempre abaixo do esperado. A descontextualização da escola com a realidade cotidiana do aluno torna o conhecimento apresentado de forma tão sem sentido que justificaria dizer que escola e a comunidade estão em dois mundos ou tempos diferentes, talvez separados por séculos.

Claro que a tecnologia não resolverá todas as dificuldades da educação, mas as tecnologias instauram uma revolução antropológica, mais do que tecnológica, pois, novas relações precisam ser desenvolvidas entre professor-aluno-saber. $\mathrm{O}$ usar a tecnologia de modo acrítico acarreta na introdução e utilização indiscriminada de tecnologia na sala de aula, sem intencionalidade pedagógica, uma simples mudança de ferramenta com as mesmas aulas descontextualizadas e sem sentido. Concordamos com Moran (2011,p.145), que os avanços da sociedade, as novas gerações, estão levando a mudança para a educação, introduzindo seus aparatos, estamos sendo mudados pelas novas gerações.

Caminhamos aceleradamente rumo a uma sociedade muito diferente que em parte vislumbramos, mas que nos reserva inúmeras surpresas. Será uma sociedade muito mais conectada, móvel, com possibilidades de comunicação, interação e de aprendizagem muito mais fascinantes ainda.

Entendemos como, Garcia (2011), que as tecnologias se tornarão a maior e mais importante pressão para impulsionar uma reforma educativa. 
Bingimlas (2009) realizou uma mega análise da literatura com o objetivo de investigar as barreiras para a integração da tecnologia na educação. Se destacaram pelo menos três barreiras,como, falta de confiança,competência e acesso aos recursos. Falta de confiança porque não é possível vivenciar na prática aquilo que se desconhece,assim como não é possível promover a aprendizagem de conteúdos que não se domina, (MELLO, 2000). Outros motivos não menos importantes foram descritos na mesma pesquisa, a dependência do material técnico ou indisponibilidade do mesmo. Além disso vários professores se preocupam com o tempo maior que a preparação de aulas, exigiria para utilizar Tecnologia da Informação e Comunicação (TICs). Alguns afirmaram inclusive que sendo assim na maioria das vezes o uso das TICs não compensa. Acreditamos que se o professor se preparar devidamente com a incorporação crítica e consciente das tecnologias digitais interativas na educação, ele não só vai ganhar tempo,como também qualidade nas horas acompanhadas dos alunos. Vamos destacar uma das áreas de ensino onde esta situação é ainda mais complexa, como é o caso do ensino de Matemática, a qual ainda representa uma das disciplinas que registra o menor uso de tecnologia pelos professores que atuam nesta área (BARCELOS, BEHAR \& PASSERINO, 2010; CALIL, 2011; GATTI \& NUNES, 2009).

\section{Contexto}

Gostaríamos de destacar que acreditamos que as tecnologias quando inseridas no contexto educacional de forma critica, consciente e planejada de forma pedagógica acarreta em ganho para o professor tanto na economia de tempo como de esforço pessoal gasto na aula expositiva que torna a sala de aula maçante e desinteressante. Não é preciso descrevermos aqui mais sobre essa geração, como Moura(2009) designou "Geração Polegar". Termo utilizado porque representa essa geração que utiliza com muita frequência o dedo polegar para digitar, clicar e mudar suas telas sensíveis ao toque, tanto de celulares como de smartphones inteligentes, tablets etc. Por isso ao analisar alguns artigos, dissertações e teses buscamos aquelas que foram desenvolvidas para esse público atual, com uso de tecnologia, com forte base metodológica e teórica com resultados testado e comprovado positivamente por seus respectivos pesquisadores, assim proporcionando ao professor condições de reproduzi-la na sua realidade profissional.

\section{Metodologia e procedimentos}

Foi utilizado a metodologia de pesquisa qualitativa de caráter bibliográfico, onde buscamos encontrar pesquisas que utilizavam alguma tecnologia, de preferência que não se repetisse a mesma tecnologia, por exemplo, encontramos alguns trabalhos que diferiam no objeto matemático mas utilizavam o Geogebra por exemplo. Sendo assim buscamos utilizar nesse trabalho apenas uma pesquisa que utilizasse o Geogebra e descartamos as outras. Além do fator tecnologia buscamos destacar as teorias e metodologias usadas no ensino de temas matemáticos desenvolvidos no ensino básico, da mesma forma buscamos evitar repetir a teoria ou metodologia nas pesquisas que destacaremos a seguir.

Para selecionar as pesquisas utilizamos primeiramente a Biblioteca Digital Brasileira de Teses e Dissertações (BDTD) onde usamos o buscador com as palavras-chave, Sequencia didática; Tecnologia; Matemática; Teorias de aprendizagem; Educação Matemática; Tecnologia educacional; Para nossa surpresa não foram muitas pesquisas encontradas, a pesquisa com o intuito de usar a tecnologia na sala de aula de forma prática não tem sido explorado como imaginávamos. Realizamos assim uma busca no site do Google Acadêmico, usando os mesmos termos usados na BDTD, e encontramos mais 
algumas dissertações e também artigos que utilizavam alguma tecnologia no ensino da matemática básica.

\section{Organização dos dados}

Após realizarmos as buscas nos sites do BDTD e do GOOGLE ACADÊMICO, selecionamos esses 12 trabalhos que atendiam o que estávamos buscando, trabalhos que poderiam ser aplicados em sala de aula, utilizando tecnologia no ensino de um objeto matemático e com suporte de uma teoria ou metodologia de ensino-aprendizagem. Os trabalhos apresentados podem servir de apoio ou inspiração para professores em sala de aula atenderem as necessidades de aprendizagem dos alunos e ainda assim também desenvolverem habilidades e competências necessárias para seu trabalho do dia a dia.

Quadro 1 - Pesquisas elaboradas com uso tecnológico e orientadas por teorias e metodologias da Educação Matemática

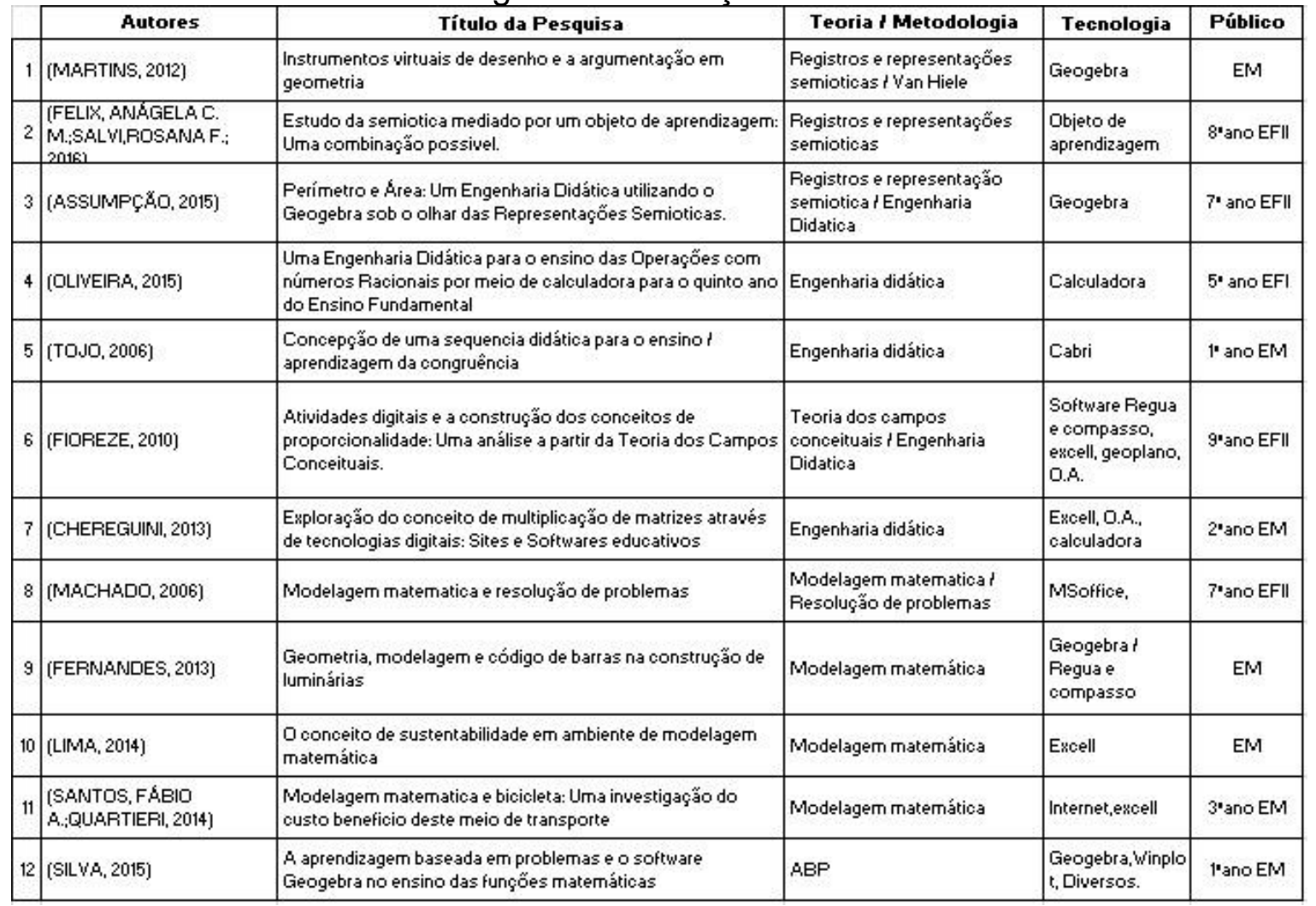

Fonte: Os autores

Contrariando nossa expectativa no quisito quantidade de pesquisas que encontramos, acabamos usando pesquisas que utilizavam a mesma metodologia de ensino e repetimos também a tecnologia usada na prática em sala de aula.

\section{Teorias e metodologias de ensino-aprendizagem}

A crise da educação reside não apenas nas péssimas condições de trabalho dos docentes, mas em vários outros fatores que se evidenciam a cada dia provocando discussões e pesquisas, como as alegações dos professores mostram, uma tentativa de fazer o trabalho minimamente com condições a atender a demanda. Erroneamente a atividade docente é encarada apenas como vocacional, onde se permiti uma grande dose de improviso e jeitinho ao dar a aula, não que a experiência não seja um fator positivo, mas no momento que enfrentamos mudanças radicais em períodos de tempo cada vez menores, 
o que foi positivo ontem pode não ser hoje com quase certeza. É imprescindível o questionamento das ideias docentes tidas como "senso comum" já presente em pesquisas na literatura nacional, como encontradas em (OSTERMANN, FERNANDA;CAVALCANTI; 2011, p.10), com frequência os professores ao iniciarem sua carreira docente tomam seus professores da educação básica ou do ensino superior como modelo para suas aulas, só que as mudanças geracionais e culturais não permitem mais esse estado de coisas.

Facilmente identificamos professores devotos de visões ultrapassadas do processo ensino-aprendizagem, que trabalham por assimilação daqueles que se espelharam ou por total falta de conhecimento de concepções pedagógicas atuais e sistematicamente presente em pesquisas da área educacional. Assim muito desgaste, acreditamos, seria minimizado se o professor estivesse a par do que se tem publicado em sua área de atuação, onde teorias, metodologias experimentadas mostrando meios e maneiras em que melhor nossos alunos podem ter sua aprendizagem maximizada. Pautados por esses experimentos cada professor se tornaria um pesquisador, contribuindo para o crescimento pessoal e profissional agregando a chama da esperança nessa maravilhosa profissão.

Queremos assim detalhar algumas teorias e metodologias que selecionamos, digase de passagem que existem outras teorias e metodologias importantíssimas que aqui não fizemos referencia por falta de espaço, tempo ou mesmo por não termos encontrado-as satisfazendo os objetivos desse trabalho. Longe de detalhar cada uma delas fizemos um pequeno resumo para que o interessado tenha um referencial mostrando onde encontrá-la e como prosseguir pesquisando pelo assunto. Assim descrevemos a teoria ou metodologia de ensino-aprendizagem com um breve resumo do trabalho realizado na prática, com seu público alvo e o objeto matemático envolvido, com destaque para os resultados obtidos a partir da aplicação em campo.

\section{Teoria de Representações Semióticas}

Pesquisas desenvolvidas por Martins (2012), trazem importantes contribuições, onde uma sequencia didática que visa o desenvolvimento argumentativo de construções geométricas construídas e analisadas por alunos do ensino médio que focaram especificamente o conceito de translação, rotação e ampliação; Felix et al (2016), que trabalham as representações a partir de uma balança virtual desenvolvendo o pensamento algébrico e resolução de equações do 1 grau, (ASSUMPÇÃO, 2015), destaca atividades desenvolvidas no geogebra com foco na geometria para alunos do 7 ano do ensino fundamental.

Nesses trabalhos é demonstrado a importância das representações semióticas nas atividades, tendo sua sequencia seguido a Teoria dos Registros de Representação Semiótica proposta pelo filósofo e psicólogo Raymond Duval no ano de 1993. Para (FELIX; SALVI, 2016, p.36), Duval diferencia os registros dos códigos por serem estes funcionalmente mais limitados que os primeiros. Quando apresentamos os registros, as atividades cognitivas fundamentais como conceitualização, resolução de problemas, raciocínio, etc; requerem a utilização de sistemas de expressão e de representação que vão além da língua natural ou imagens, desenvolvendo as capacidades para que o aluno participe e dirija seu processo de aprendizagem (DUVAL, 2003). As representações tornamse assim importantes no processo de aprendizagem pois não possuem apenas a função de comunicação mas são fundamentais para as atividades cognitivas do pensamento. A abstração do objeto matemático não está acessível á percepção, sendo necessário assim para sua compreensão o uso de representações. "Não há conhecimento que possa ser mobilizado por um sujeito sem uma atividade de representação" (DUVAL, 2009, p.29). 
Destacamos os principais registros de representação semiótica como, a língua natural, as escrituras algébricas, as figuras geométricas e as representações gráficas.

No ensino de matemática as mudanças de registros facilitam a compreensão, bem como, a descoberta pelo aprendiz na atividade intelectual da elaboração como na transformação de representações semióticas, é bom distinguirmos dois tipos de transformação das representações: o tratamento e a conversão.

Um tratamento é uma transformação de representação interna a um registro de representação ou a um sistema.O cálculo é um tratamento interno ao registro de uma escritura simbólica de algarismo e de letras: ele substitui novas expressões em expressões dadas no mesmo registro de escritura de números (DUVAL, 2009, p.57)

Tratamento é a transformação de uma representação em uma outra do mesmo registro, como por exemplo, escrever um número fracionário 3/9 em uma fração equivalente 1/3; Uma conversão é a transformação de uma representação de um registro em uma outra representação de outro registro,por exemplo, um registro fracionário $1 / 2$ convertido em um registro decimal 0,5 ; conservando pelo menos a referencia ao mesmo objeto ou a mesma situação representada, como afirma (ALMOULOUD, 2007, p.72).

\section{Engenharia Didática}

No trabalho de Oliveira (2015), além do uso da Teoria do Registro de Representação Semiótica é usado também a Engenharia Didática e a Teoria das Situações Didáticas na elaboração de uma sequencia didática para ensino de operações com números racionais utilizando calculadora, para alunos do $5^{\circ}$ ano do ensino fundamental; Tojo (2006), elaborou uma sequência para investigar como alunos do $1^{\circ}$ ano do E.M. se apropriam do conceito de congruência utilizando o Cabri-géométre; Fioreze ( 2010), faz uma investigação utilizando atividades digitais com o software Régua e Compasso, planilhas eletrônicas, Geoplano e dois Objetos de aprendizagem criados pelo grupo RIVED, para aprendizagem dos conceitos de proporcionalidade; Chereguini (2013), utiliza softwares, sites e objetos de aprendizagem para uma sequência didática no ensino de multiplicação de matrizes, entre eles o Microsoft Excell e objetos de aprendizagem desenvolvidos pela UFF- Universidade Federal Fluminense entre outros.

A Engenharia Didática, vista como metodologia de investigação, caracteriza-se por um esquema experimental baseado em realizações didáticas na sala de aula, isto é, na concepção, na realização, na observação e na análise de sequências de ensino; Considera os conhecimentos prévios dos alunos, e parte deles, para a construção de um saber autentico e significativo.

A engenharia didática emergiu no inicio dos anos 80 foi comparada por Artigue (1988) com o trabalho de um engenheiro. Possui princípios que partem da teoria cognitivista. Ela é constituída de 4 fases: Análises preliminares, concepção e análise á priori, aplicação da sequencia didática e a analise a posteriori seguida de uma possível validação

\section{1ํㅡㄹ Fase: Análises Preliminares}

Sobre essa primeira fase, Pais (2002, p. 101) diz: "Para melhor organizar a análise preliminar, é recomendável proceder a uma descrição das principais dimensões que 
definem o fenômeno a ser estudado e que se relacionam com o sistema de ensino, tais como a epistemologia cognitiva, pedagógica, entre outras". Cada uma dessas dimensões participa na constituição do objeto de estudo. Para uma análise preliminar eficaz, como indicado por Alves (2016), a pesquisa em livros didáticos, artigos de congressos, vídeos e sites pode fornecer dados importantes para a criação da sequência didática prevendo entraves e obstáculos no campo de ensino potencializando o objetivo geral da pesquisa.

\section{2ª Fase: Concepção e análise a priori das Situações Didáticas}

Nessa fase devem ser levados em consideração os seguintes pontos: a descrição do objeto e a previsão de melhorias para o ensino do determinado conteúdo no processo de ensino e aprendizagem. Apontamos também o problema detectado na fase anterior e são construídas hipóteses que serão verificadas na prática investigativa da sequência didática elaborada. É nessa fase que se inicia o processo de validação, recebendo e analisando as situações didáticas antes da aplicação no ambiente escolar tendo por base os estudos preliminares. Se faz a predição do que se espera acontecer na implementação da sequencia didática.

\section{3ํㅡㄹ Fase: Experimentação de uma sequência didática}

Uma seqüência didática é formada por um certo número de aulas planejadas e analisadas previamente com a finalidade de observar situações de aprendizagem, envolvendo os conceitos previstos na pesquisa didática. Essas aulas são também denominadas sessões, tendo em vista o seu caráter especifico para a pesquisa. Em outros termos, não são aulas no sentido da rotina da sala de aula. Tal como acontece na execução de todo projeto, é preciso estar atento ao maior número possível de informações que podem contribuir no desvelamento do fenômeno investigatório, Pais (2002, p. 102). A aplicação do instrumento de pesquisa deve ter seu registro seja por registro de observações por meio de diário, de gravações em áudio e vídeo, produções escritas dos alunos etc.

\section{4ํㅡㄹ Fase: Análise a posteriori e validação}

Nessa fase é verificado se o que era almejado com o projeto foi alcançado, ou seja, se o aprendizado foi consolidado e o aluno alcançou certa autonomia com o seu desenvolvimento, determinando assim a validação, ou não, da sequência didática aplicada. A fase de validação se dá durante todo o processo de desenvolvimento do projeto. Cabe ao docente confrontar os dados obtidos na análise a priori e na análise a posteriori e confirmar ou refutar as hipóteses que foram levantadas no início do projeto.

\section{Teoria das Situações Didáticas}

Para apoiar a Engenharia didática alguns trabalhos,como de Oliveira (2015), explora as atividades em sala orientado pela Teoria das Situações Didáticas, onde possui quatro fases de ensino prevista: Ação, Formulação, Validação e Institucionalização. Essa Teoria foi desenvolvida pelo Francês Guy Brousseau (1986), onde ele buscou criar um modelo da interação entre o aprendiz, o saber e o "milieu" (meio) no qual a aprendizagem deve se desenvolver.A proposta de Brousseau é de que o trabalho intelectual do aluno deve ser de investigação cientifica, considerando que é capaz de formular, provar, construir modelos, linguagem e de trocar essas informações com outros alunos. Um caráter importante dessa Teoria é a criação de um ambiente experimental para a investigação em matemática, de tal maneira que o aluno pode reproduzir em escala elementar, os passos semelhantes executados pelo matemático. (ALMOULOUD,2007,p.31). 
As relações do professor com o aluno envoltos com o saber em sala de aula, precisam estar em condições para consolidação da aprendizagem através de situações problemas, no momento que são desenvolvidas na sala de aula. A teoria das Situações Didáticas permitem a intervenção tanto do aluno como do professor. Segundo Almouloud (2007) a teoria das Situações Didáticas se apoia em três hipóteses:

O aluno aprende adaptando-se a um milieu que é fator de dificuldades, de contradição e de desequilíbrio, um pouco como acontece na sociedade humana. Esse saber, fruto da adaptação do aluno, manifesta-se pelas respostas novas, que são a prova da aprendizagem, Brousseau (1986, p.49). Esta hipótese é uma referencia á epistemologia construtivista de Piaget. $O$ milieu não munido de intenções didáticas é insuficiente para permitir a aquisição de conhecimentos matemáticos pelo aprendiz. Para que aja uma intencionalidade didática, o professor deve criar e organizar um milieu no qual serão desenvolvidas as situações suscetíveis de provocar essas aprendizagens. A terceira hipótese postula que esse milieu e essas situações devem engajar fortemente os saberes matemáticos envolvidos no processo de ensino e aprendizagem. (BROUSSEAU, 1986 apud ALMOULOUD, 2007, p.32).

Destacando as quatro fases de ensino da Teoria das Situações Didáticas temos:

\section{Ação}

É apresentado para o aluno um problema que na melhor solução é o conteúdo a ser ensinado. $O$ aluno passa então a agir para resolver esse problema, uma boa situação é a que o aluno se acha empenhado e comprometido para a solução do problema, aprendendo assim ao agir.Criando assim uma aprendizagem por adaptação.

\section{Formulação}

O aluno está em situação em que pode dividir com outras pessoas, trocando informações, seja oral ou escrita, num processo dialético criando assim modelos explícitos que podem ser formulados com sinais e regras comuns ou novas. Concordamos que

O objetivo da dialética da formulação é a troca de informações. Por exemplo, se o aluno deve agir e não dispõe de toda a informação e seu parceiro no jogo dispõe das informações que lhe faltam, pode haver, nessas trocas, julgamentos, debates de validade, sem que isto constitua necessariamente uma situação de formulação. (ALMOULOUD, 2007, p.38)

Se aluno conseguir formalizar os conhecimentos, regras e conceitos por mais simples que sejam sobre as suas ideias terá avançado e muito na construção do seu conhecimento. 


\section{Validação}

O aluno deve mostrar a validade das suas possíveis soluções, por isso a importância dele descrever e discutir com outros sua solução de descrita de forma clara e precisa, ali no debate e nas discussões sua formalização será aceita ou refutada.

\section{Institucionalização}

O professor ao receber as conclusões de seus alunos faz o confronto entre os conhecimentos apresentados institucionalizando o saber ensinado. Após esse momento 0 conhecimento passa a ser oficializado pelo professor onde os alunos poderão incorporá-lo aos seus esquemas mentais e disponivel para a resolução de problemas matemáticos.

\section{Modelagem e Resolução de Problemas}

Utilizando a metodologia de Modelagem e resolução de problemas, Machado (2006) trabalhou com alunos do 5 ano do ensino fundamental em um projeto piloto, investigando, se alunos com dificuldade em matemática e falta de interesse, poderiam ter suas atitudes alteradas e se interessariam ao se envolverem com uma modelagem que discutia a reforma da quadra de esportes abordando: Sistema métrico; Frações; Números decimais; Perímetro,área e volume de figuras retangulares; Com a turma do 6 ano foi decidido após discussões que seria feito um trabalho sobre o transporte escolar publico e gratuito.

Em Fernades (2013), foi trabalhado com alunos do $2^{\circ}$ ano do Ensino Médio a construção de uma luminária, trabalhando geometria plana e es pacial e função. Foi utilizado o geogebra e pode ser usado o software Régua e Compasso.

Outros trabalhos que utilizaram a modelagem como, Lima (2014), Santos et al (2014),entre outros, trazem uma idéia do uso e bons resultados dessa metodologia. A modelagem matemática tem como objetivo levar o aluno a enxergar no seu dia a dia a matemática antes ensinada na escola descontextualizada e sem sentido. $O$ professor encontra na modelagem situações reais na aula de matemática aliando teoria e prática.

De acordo com Bassanezi, "Modelagem matemática consiste na arte de transformar problemas da realidade em problemas matemáticos e resolvê-los interpretando suas soluções na linguagem do mundo real". (BASSANEZI, 2002, p.16).

A Aprendizagem por Resolução de problemas (PBL ou ABP) traz contribuições interessantes como o trabalho de Silva (2015), onde pesquisa Funções com alunos do $1^{\circ}$ ano do Ensino Médio com auxilio do geogebra, mas possui algumas indicações de softwares matemáticos interessantes. Segundo Torres \& Vasconcelos (2013):

A aprendizagem Baseada na Resolução de Problemas é uma metodologia centrada no aluno cujo processo se inicia com a apresentação de um problema real cuja resolução é pessoal, social ou ambientalmente importante para o aluno. Implica uma mudança paradigmática em termos educacionais dado que os alunos se tornam construtores do seu conhecimento e o professor exerce o papel de mediador facilitando a procura da resolução do problema (TORRES \& VASCONCELOS, p.48, 2013) 
As escolas de medicina foram as primeiras a usarem essa metodologia, nos Estados Unidos, no inicio da década de 1950. Por conta de seu histórico e de seus pressupostos (aluno ativo, experimentalismo, ensino contextualizado) outras áreas como as tecnológicas e a educação se interessam pelo seu uso. No Brasil a Faculdade de Medicina de São Carlos adota essa abordagem desde 2007.

A educação a recebe como promotora de reflexão pelos alunos ao se depararem com seus desafios. A melhora no desenvolvimento acadêmico e principalmente a promoção de autonomia da aprendizagem e de trabalho em equipe. Lembrando sempre que como nos apresenta Freitas (2012):

"A aprendizagem Baseada em Problemas também tem o propósito de criar hábitos de estudo e de pensamento pelo método da experiência reflexiva, melhorar o desempenho escolar dos alunos e, principalmente promover autonomia de aprendizagem e de trabalho em equipe, tal como se espera que ocorra na vida profissional."(FREITAS, p.405, 2012).

\section{Considerações finais}

Observamos que o trabalho docente está repleto de dificuldades e transições que precisam ser melhor estudados para que encontremos o equilíbrio almejado entre as aspirações e mudanças ocasionadas pelas novas gerações. As tecnologias chegaram e ela mudará o ambiente escolar, a apropriação pelo professor desse aparato tecnológico pode ajuda-lo a minimizar as muitas dificuldades como apresentadas no inicio deste trabalho, tempo, capacitação, envolvimento dos alunos etc. As teorias e metodologias apresentadas são uma pequena parte desse arsenal que o professor pode tomar para si ao preparar suas aulas. A revisão desses trabalhos mostra atividades preparadas de forma simples, com os mais simples aparatos tecnológicos, Fiorentini (2006), ao mencionar a importância da Educação Matemática vem enfatizando que:

Poderíamos dizer que a EM caracteriza-se como uma práxi que envolve o domínio do conteúdo específico (a matemática) e o domínio de ideias e processos pedagógicos relativos á transmissão/assimilação e/ou á apropriação /construção do saber matemático escolar. Entretanto, sendo a prática educativa determinada pela prática social mais ampla, ela atende a determinadas finalidades humanas e aspirações sociais concretas.(FIORENTINI, p.05, 2006)

Ponderamos assim que a tecnologia deve vir acompanhada de uma reflexão pedagógica, como os trabalhos aqui apresentados embasadas teórica e metodologicamente, buscando se apropriar daquilo que já foi experimentado de alguma forma e demonstrado seu sucesso na prática. Não que o professor com sua capacidade de pesquisador não possa inovar e assim abrir novas possibilidades para seus pares, por isso a necessidade que as mais novas descobertas e soluções cheguem aos professores, que se interessem por revistas cientificas ou pesquisas acadêmicas de suas áreas, mas que estejam informados com o que tem de mais atual para seu crescimento profissional e sucesso na aprendizagem de seus alunos. Entender como se dá a construção do conhecimento é parte essencial da profissão do professor, as mais novas descobertas são 
apresentadas constantemente em artigos, dissertações, teses, apresentadas em congressos, etc.; o professor não pode perder o espírito pesquisador e deixar de lado tantas conquistas e avanços que acabam por ficar anos até chegarem nas salas de aula.

As diversas teorias e metodologias atendem de alguma forma a grande população de estudantes, com suas expectativas e desejos nas mais diferenciadas formas, basta que o professor conhecendo seus alunos atenda essa demanda com profissionalismo e dedicação se preparando e preparando suas aulas. Os exemplos aqui deixados podem ser utilizados na integra ou adaptados de acordo com a necessidade e possibilidade do professor, mas esses são apenas uma pequena parte disponível, cada professor pode garimpar pelos mais diferentes meios e locais outros que satisfaçam suas necessidades.

\section{Referências}

ALMOULOUD, S. A.. Fundamentos da Didática da Matemática. Editora UFPR. Curitiba.2007.

ALVES, F. R. V. . Engenharia Didatica para a generalização da sequência de Fibonacci: Uma experiência num curso de licenciatura. Educação Matemática Pesquisa São Paulo, v. 18, n. 1, p. 61-93, 2016.

ASSUMPÇÃO, P. G. S. DE; Perímetro e Área: Uma Engenharia Didática utilizando o Geogebra sob o olhar das Representações Semióticas. Santa Maria - RS, Brasil: Universidade Federal de Santa Maria, 2015.

CHEREGUINI, A. L. C. . EXPLORAÇÃO DO CONCEITO DE MULTIPLICAÇÃO DE MATRIZES ATRAVÉS DE TECNOLOGIAS DIGITAIS : SITES E SOFTWARES EDUCATIVOS. São carlos -SP, Brasil: Universidade Federal de São Carlos, 2013.

FELIX, ANÁGELA C. M.;SALVI, R. F. . Estudo da semiótica mediado por um objeto de aprendizagem: uma combinação possível. REVEMAT, v. 11, n. 1, p. 36-53, 2016.

FERNANDES, E. A. . Geometria, Modelagem e Código de Barras na construção de Luminárias. São Carlos/SP, Brasil: Universidade Federal de São Carlos, 2013.

FIORENTINI, D. . Investigação em Educação Matemática: Percursos Teóricos e Metedológicos. Campinas, SP. Autores Associados, 2006. (Coleção Formação de Professores).

FIOREZE, L. A. . Atividades Digitais e a Construção dos Conceitos de Proporcionalidade: Uma Análise a Partir da Teoria Dos Campos Conceituais. Porto Alegre - RS, Brasil: Universidade Federal do Rio Grande do Sul, 2010.

FREITAS, R. A. M. M.; Ensino por problemas: Uma abordagem para o Desenvolvimento do aluno. Educação e Pesquisa, São Paulo, v.38, n.2 , p.403-418, abr/jun. 2012

LIMA, M. A. . O conceito de sustentabilidade em ambiente de modelagem matemática. Porto Alegre - RS, Brasil: Universidade Federal do Rio Grande do Sul, 2014. 
MACHADO, E. S. . Modelagem Matemática e Resolução de Problemas. Porto Alegre RS, Brasil: Pontificia Universidade Católica do Rio Grande do Sul, 2006.

MARTINS, F. L. F. . Instrumentos virtuais de desenho e a argumentação em geometria. Porto Alegre - RS: UFRGS, 2012.

OLIVEIRA, A. S. DOS S. . Uma Engenharia Didatica para o Ensino das Operacoes com Numeros Racionais por meio de calculadora para o quinto ano do ensino fundamental. São Paulo, Brasil: Pontifícia Universidade Católica, 2015.

OSTERMANN, FERNANDA;CAVALCANTI, C. J. DE H. . Teorias de aprendizagem. UNIVERSIDADE ABERTA, p. 58, 2011.

SANTOS, FÁBIO A.;QUARTIERI, M. T. . Modelagem Matemática e bicicleta: Investigação do custo benefício deste meio de transporte. Revista de Educação, Ciências e Matemática, v. 4, n. 3, p. 67-78, 2014.

SILVA, J. C. E. DA. A aprendizagem baseada em problemas e o software Geogebra no Ensino das Funções Matemáticas. São Paulo/SP, Brasil: Universidade Cruzeiro do Sul, 2015.

TOJO, B. N. . Concepção de uma sequência didática para o ensino/ aprendizagem da congruência. São Paulo/SP, Brasil: Pontifícia Universidade Católica, 2006.

Submissão: 01/04/2017

Aceite: $29 / 06 / 2017$ 